\title{
Trend Analysis And Seasonality Of Tuberculosis Among Patients At The Hiwot Fana Specialized University Hospital, Eastern Ethiopia: A Retrospective Study
}

This article was published in the following Dove Press journal:

Risk Management and Healthcare Policy

\author{
Dagne Bodena' \\ Zerihun Ataro $\mathbb{D}^{2}$ \\ Tewodros Tesfa $\mathbb{( D D}^{2}$ \\ 'Hiwot Fana Specialized University \\ Hospital, College of Health and Medical \\ Sciences, Haramaya University, Harar, \\ Ethiopia; ${ }^{2}$ Department of Medical \\ Laboratory Sciences, College of Health \\ and Medical Sciences, Haramaya \\ University, Harar, Ethiopia
}

Purpose: Tuberculosis (TB) is one of the top 10 leading killer diseases in developing countries, particularly in Sub-Saharan Africa, including Ethiopia. Thus, this study aimed to assess the trend analysis and seasonality of TB at Hiwot Fana Specialized University Hospital, Eastern Ethiopia.

Methods and patients: A hospital-based retrospective study was conducted on 8,001 patients by reviewing all available patients' data from January 1, 2015 to April 30, 2019, at the Hiwot Fana Specialized University Hospital, Eastern Ethiopia. Socio-demographic characteristics and results of the GeneXpert assay were taken from the registration book. The data were entered into EpiData 3.1 and analyzed by using the statistical Package for Social Sciences (SPSS) version 20.

Results: From a total of 8,001 samples tested using Genexpert, the overall prevalence of Mycobacterium tuberculosis and rifampicin resistance was found to be 1,254 (15.7\%) and 53 (4.1\%), respectively. A decreasing trend of TB prevalence was observed, and decreased from $19.3 \%$ in $2015,18.6 \%$ in 2016 , to $18.4 \%$ in $2017,13.5 \%$ in 2018 and down to $13.0 \%$ in 2019 $(P$-value $<0.001)$. The maximum number of TB cases were reported during autumn $(454,17.1 \%)$ and summer $(310,17.2 \%)$ compared to other seasons of all the study period. Being between the ages of $15-29$ years (adjusted odds ratio $(A O R)=1.7,95 \%$ confidence interval $(\mathrm{CI})=1.41-1.98)$, of male gender $(\mathrm{AOR}=0.84,95 \% \mathrm{CI}=0.75-0.96)$, experiencing a relapse of $\mathrm{TB}$ ( $\mathrm{AOR}=0.51,95 \%$ $\mathrm{CI}=0.35-0.78)$, and being $\mathrm{HIV}$ positive $(\mathrm{AOR}=0.51,95 \% \mathrm{CI}=0.3-0.86)$ were found to be factors associated with high proportion of tuberculosis.

Conclusion: Prevalence of TB has decreased year to year between January 2015 and April 2019. However, a high percentage of patients are still testing positive for TB with different seasonal variations. Thus, understanding and managing TB in seasonal variation, controlling relapse of TB, and screening of all HIV positive patients are recommended steps to reduce the transmission of tuberculosis in Ethiopia.

Keywords: tuberculosis, trends, seasonality, Eastern Ethiopia

\section{Background}

Tuberculosis (TB) is a worldwide chronic infectious disease, mainly caused by Mycobacterium tuberculosis. It is highly transmitted by untreated smear-positive pulmonary tuberculosis when the infectious individual expels droplets of the bacilli which are produced during coughing, singing, and sneezing. ${ }^{1}$ The disease occurs
Hiwot Fana Specialized University

Hospital, College of Health And Medical

Sciences, Haramaya University, PO Box

235, Harar, Ethiopia

Tel +251910127241

Email dagne2004bodena@gmail.com 
when the bacteria overcome immune defenses, multiply, and become large enough in number to cause tissue damage. TB can attack all parts of the body. It typically attacks the lungs (pulmonary TB) as well as other parts of the body (extra pulmonary TB). ${ }^{2}$

Globally, about one-third of the world's population has dormant M. tuberculosis and hence is at risk of getting an illness. That hinders the socio-economic development of a country, as $75 \%$ of people with $\mathrm{TB}$ are within the economically productive age group of 15-54 years. ${ }^{3}$

The World Health Organization 2018 global TB report revealed that nearly 10 million people had developed TB disease in 2017. Of these, 3.2 million were women, 5.8 million were men, and 1 million were children. There were also an estimated 1.3 million deaths caused by TB, and 300,000 deaths occurred in the case of TB-HIV coinfection in $2017 .^{4}$

Globally, about $87 \%$ of all TB incident cases were covered by 30 high TB burdened countries. Among these, Africa shares one third by having nine countries from 22 high burdened countries, and Ethiopia falls under this category. ${ }^{4}$ Even though there has been a major decline in the incidence and TB associated death rates in Ethiopia, still the country is highly affected and stands third in Africa, with an annual estimation of TB incidence of 172/100,000 and a death rate of 24/100,000 population in 2017. Moreover, among those with low socio-economic status, living conditions, poor nutrition, and lack of awareness to seek early diagnosis, TB is ranked as the third most common cause of hospital admission and the second most common cause of death from the top ten diseases in Ethiopia. ${ }^{5-7}$

Even though TB was not well defined as a seasonal variation in different countries, some reports revealed that a peak of TB cases occurred in the summer ${ }^{8,9}$ and spring, ${ }^{10,11}$ while it was lower in December and a peaked in July in Uganda, ${ }^{12}$ with a rise in autumn in Ethiopia. ${ }^{13}$ TB was confirmed to be a seasonal disease with a low rate in the second and high in the fourth quarter of the calendar year in Ethiopia. ${ }^{13}$ Geographical variation and healthcare-seeking behavior of patients cause high TB infection in the winter that profound the symptom and diagnosis of a disease in autumn and summer season. ${ }^{14}$

Trend analysis and an assessment of TB seasonality help to allocate resources appropriately regarding clinical evaluation and research enrollment in high TB burdened areas. However, limited research has been reported from Ethiopia. Therefore, this study aimed to assess the seasonality and trend analysis of TB among patients attending the Hiwot Fana Specialized University Hospital.

\section{Methods And Materials}

\section{Study Design, Area, And Period}

A hospital-based retrospective study was conducted among patients diagnosed for TB by using data recorded from January 1, 2015 to April 30, 2019, at Hiwot Fana Specialized University Hospital, Harar, Eastern Ethiopia. Harar town is one of the historical places which found $526 \mathrm{~km}$ east of Addis Ababa, the capital city of Ethiopia. Based on the central statistical agency of 2007, the total population of Harari Regional state was 183,415 , of whom 91,099 were females and 92,316 were males. It has nine districts, three urban and six rural. There are six hospitals (four governmental and two private), eight public health centers, and 20 health posts in the region.

Hiwot Fana Specialized University Hospital (HFSUH) is one of the oldest hospitals in Ethiopia, which was established during the occupation of Italian soldiers (1928-1933). Currently, the hospital serves about 5.2 million people around Harar and neighboring regions like Dire Dawa administrative council, Oromiya, and Ethiopian Somali Regional State.

It serves as a teaching center of eastern Ethiopia and delivers different health services to the community like internal medicine, surgery, gynecology and obstetrics, TB/ HIV, etc. In the hospital, the TB prevention and control program is coordinated by TB clinic staff with the Harari regional health bureau.

\section{Study Population}

The study population for this study was all presumptive TB patients attending Hiwot Fana Specialized University Hospital. We have included those presumptive TB patients with complete records of their demographic, clinical, and laboratory data from January 1, 2015 to April 30, 2019. Those patients with incomplete data were excluded from the study.

\section{Laboratory Investigation And Data Collection Procedure}

Laboratory investigations by GeneXpert MTB/RIF assay were performed as per the manufacturer's guidelines and data was collected using an excel spreadsheet from the 
record/registration book. The collected data were crosschecked twice by the investigator to reduce error.

\section{Statistical Data Analysis}

Data were coded and entered into EPI-data version 3.1 and analyzed by using SPSS version 20. Descriptive statistics of different variables were determined and presented in the form of texts, graphs, and tables. Summary measures such as percentages and mean were used to generalize the results accordingly. Bivariate logistic regression was carried out to identify the associated factors with TB. Variable with $P$-value $\leq 0.25$ was a candidate for the multivariate analysis. Finally, multivariate logistic regression analysis was performed for adjusted odds ratio with $95 \%$ confidence intervals and variables with a $P$-value $<0.05$ were declared as statistically significant.

\section{Ethical Consideration}

The study clearance was obtained from the College of Health and Medical Sciences, the Institutional Research Ethics Review Committee (IRERC), Haramaya University. Permission was obtained from Hiwot Fana Specialized University Hospital (HFSUH) where the study was conducted. Patient and parental consent to review their medical records was not required since the study is retrospective. There was compliance with the 1964 Helsinki declaration and its later amendments or comparable ethical standards.

The information provided from patients' recorded data was kept confidential. No names were involved in the data analysis process; only codes were used to identify the study populations.

\section{Results}

\section{Socio-Demographic, Clinical Characteristics, And Laboratory}

\section{Diagnosis Of The Study Participants}

From a total of 9,060 TB clinically suspected patients that have submitted their samples for TB diagnosis, $8,001(88.3 \%)$ had complete data and were included in this study. The majority of the participants' HIV status was unknown in 7,624 (95.3\%). The mean age of participants diagnosed for TB was $29.89( \pm 17.55)$ years ranging from 1 month to 95 years old, of which 4,363 $(54.5 \%)$ were males and $3,638(45.5 \%)$ were females. The majority of them were in the age group of $\geq 15$ years old $(6,600,82.5 \%)$. Most of the study participants
Table I Socio-Demographic And Clinical Characteristics Of The Study Participants At Hiwot Fana Specialized University Hospital, Eastern Ethiopia, January 2015-April 2019

\begin{tabular}{|l|l|l|}
\hline Characteristics & Number & Percentage \\
\hline Age (years) & & \\
$\leq 14$ & 1,401 & 17.5 \\
$15-29$ & 2,569 & 32.1 \\
$30-44$ & 2,287 & 28.6 \\
$\geq 45$ & 1,744 & 21.8 \\
\hline Sex & & \\
Male & 4,362 & 54.5 \\
Female & 3,639 & 45.5 \\
\hline HIV status & & \\
Reactive & 73 & 0.9 \\
Non-reactive & 304 & 3.8 \\
Unknown & 7,624 & 95.3 \\
\hline History of TB & & \\
New & 7,896 & 98.7 \\
Previous Rx & 105 & 1.3 \\
\hline Site of sample & & \\
Extra-Pulmonary & 142 & 82.3 \\
Pulmonary & 7,859 & 79.5 \\
\hline Residence & & \\
Urban & 6,362 & \\
Rural & & \\
\hline
\end{tabular}

Abbreviations: Rx, retreatment; HIV, human immunodeficiency virus; TB, Tuberculosis.

lived in rural $(6,362,79.5 \%)$ areas and 1,639 (20.5\%) were urban dwellers (Table 1).

The overall proportion of biologically confirmed TB cases, detected by GeneXpert MTB/RIF assay, was $15.7 \%$ (95\% $\mathrm{Cl}=14.9-16.5)$ in all age groups and the overall proportion of rifampicin resistance was $4.2 \%(53 / 1,254)$.

\section{Trends Of Tuberculosis}

The proportion of TB detected by GeneXpert MTB/RIF assay was decreased in all consecutive years of the study period. The high rate of TB was presented $(19.3 \%)$ in 2015 and with a low rate, 219 (13\%) in 2019 ( $P$-value $<0.001)$. Rifampicin resistance was slightly similar to $14(7.4 \%)$ in 2015 , and $16(8.1 \%)$ in 2017. But this decreased from 2017 to 2019 to reach 2 (0.9\%) (Figure 1).

Male participants have a higher proportion of TB cases than female participants and the age category of 15-29 


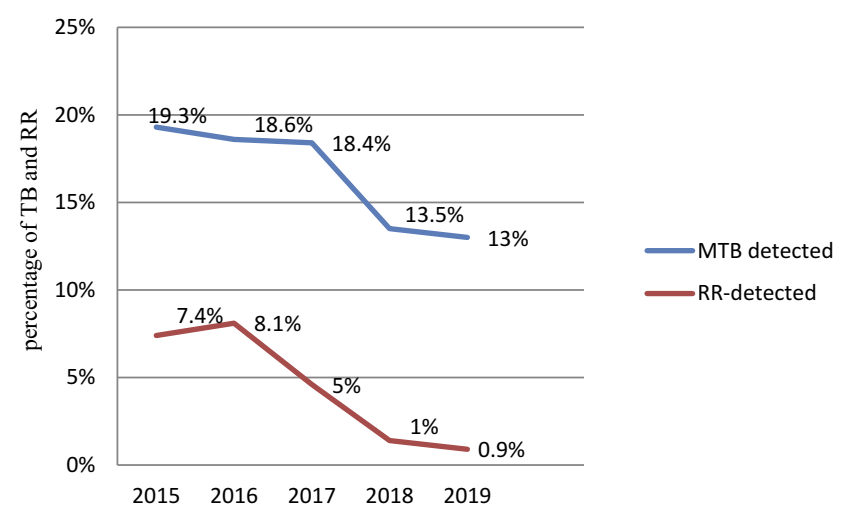

Figure I Trend of TB and rifampicin resistance at Hiwot Fana Specialized University Hospital, Eastern Ethiopia, January 2015-April 2019.

was highly affected compared to the others. The TB positivity rate was high in previously treated patients compared to the new ones (Table 2).

\section{Seasonality Of Tuberculosis}

From January 2015 to April 2019 of the study periods, there were more than 16 seasons that a total of 8,001 participants were recruited for TB diagnosis. The highest TB case was recorded in May followed by June and August. The lowest TB case was observed in January and December (Table 3).
In general, the maximum proportion of TB was reported in summer $(310,17.2 \%)$ and autumn (454, 17.1\%). Rifampicin resistant of MTB was registered at all seasons without forming great fluctuation (Figure 2).

\section{Factors Associated With Tuberculosis}

A high proportion of TB positive cases was documented with patients who lived in rural areas $(1,015,16.0 \%)$ compared to urban dwellers $(239,14.4 \%)$. The positivity rate of a sample taken from the pulmonary site $(1,235$, $15.7 \%$ ) was slightly higher compared to the extra pulmonary site $(199,13.4 \%)$. From bivariate analysis, sex, age, history of TB, HIV status, and residence of participants were recruited for multivariate analysis $(P$-value $<0.25)$. In multivariate analysis, sex, age, history of TB, and HIV status of patients were associated with TB (Table 4).

\section{Discussion}

Tuberculosis (TB) is a disease that continues to be a major public health problem amongst the ten top disease causes of mortality. Millions of people continue to fall sick with TB each year, particularly in developing countries. ${ }^{4,15}$ In this study, the overall proportion of TB detected by Xpert assay was found to be $15.7 \%$. This is comparatively similar to a study conducted at Felege Hiwot and Debre Tabor Hospitals, Northwest

Table 2 Trend Of Tuberculosis By Different Characteristics Of The Study Participants At Hiwot Fana Specialized University Hospital, Eastern Ethiopia, January 2015-April 2019

\begin{tabular}{|c|c|c|c|c|c|c|c|}
\hline \multicolumn{2}{|c|}{ Characteristics } & \multicolumn{5}{|l|}{ Years } & \multirow[t]{2}{*}{ Total } \\
\hline & & \multirow{2}{*}{$\frac{2015}{\mathrm{~N}(\%)}$} & \multirow{2}{*}{$\frac{2016}{\mathrm{~N}(\%)}$} & \multirow{2}{*}{$\frac{2017}{\mathrm{~N}(\%)}$} & \multirow{2}{*}{$\begin{array}{l}2018 \\
\mathrm{~N}(\%)\end{array}$} & \multirow{2}{*}{$\begin{array}{l}2019 \\
N(\%)\end{array}$} & \\
\hline & & & & & & & N (\%) \\
\hline Sex & Male & $112(20.9)$ & $120(19.3)$ & $219(14.8)$ & 153 (13.9) & $123(13.4)$ & 727 (I6.7) \\
\hline & Female & $77(17.3)$ & 78 (I7.7) & $150(14.8)$ & $126(12.9)$ & $96(12.5)$ & $527(14.5)$ \\
\hline \multirow[t]{4}{*}{ Age (years) } & $\leq 14$ & $25(15.1)$ & $18(11.5)$ & $53(16.1)$ & $60(14.2)$ & $41(12.6)$ & $197(14.1)$ \\
\hline & $15-29$ & $66(22.3)$ & $86(23.5)$ & 159 (2I.7) & $110(15.6)$ & $80(17.0)$ & $501(19.5)$ \\
\hline & $30-44$ & $64(20.2)$ & $59(17.9)$ & 91 (16.3) & $61(10.9)$ & $58(11.1)$ & $333(14.6)$ \\
\hline & $\geq 45$ & $34(16.8)$ & $35(16.6)$ & 66 (11.3) & $48(12.4)$ & 40 (II.I) & $223(12.8)$ \\
\hline \multirow[t]{3}{*}{ HIV status } & Reactive & $3(100)$ & $9(26.5)$ & $6(21.4)$ & I (I2.5) & - & $19(26)$ \\
\hline & NR & $5(18.5)$ & $14(35.9)$ & $43(18.1)$ & $I(100)$ & $I(100)$ & $64(2 I)$ \\
\hline & Unknown & $18 \mid(19)$ & 175 (I7.7) & $320(16.5)$ & 277 (13.4) & $218(13)$ & $\mathrm{I}, 17 \mathrm{I}(15.4)$ \\
\hline \multirow[t]{2}{*}{ History of TB } & New case & $186(19.1)$ & $188(18.3)$ & $358(16.7)$ & $276(13.3)$ & $217(12.9)$ & $1,225(15.5)$ \\
\hline & Relapse & $3(37.5)$ & $10(24.9)$ & II (20.4) & $3(60)$ & $2(50)$ & $29(27.6)$ \\
\hline \multirow[t]{2}{*}{ Residence } & Rural & $154(19.6)$ & $142(17.9)$ & $315(17.7)$ & $226(14.1)$ & $180(13.1)$ & $1,017(16)$ \\
\hline & Urban & $35(17.8)$ & $56(20.9)$ & $54(12.8)$ & $53(11.2)$ & 39 (12.9) & $237(14.3)$ \\
\hline
\end{tabular}

Abbreviations: NR, non-reactive; $\mathrm{N}$, number of mycobacterium tuberculosis cases detected. 


\begin{tabular}{|c|c|c|c|c|c|c|c|c|}
\hline & & & 离 & $\begin{array}{l}\text { ¿ } \\
z\end{array}$ & 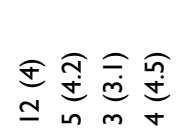 & 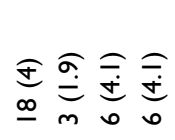 & 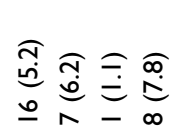 & 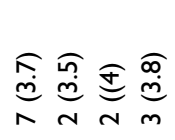 \\
\hline & & & 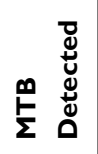 & z & 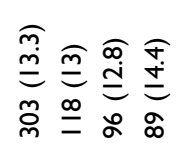 & 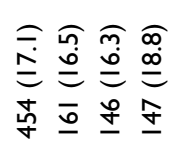 & 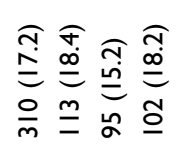 & 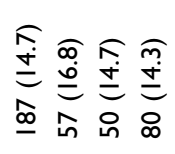 \\
\hline & & & 离 & z & 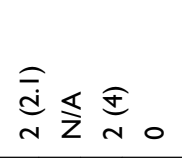 & $000 \frac{\mathbb{Z}}{1}$ & 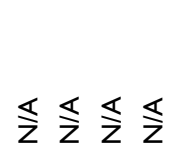 & 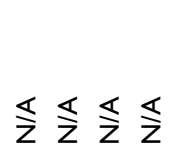 \\
\hline & & & 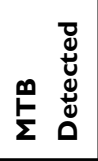 & z & 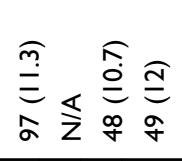 & 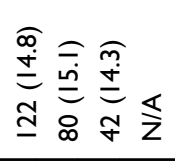 & $\widehat{z} \ll \ll \ll$ & $\widehat{z} \ll \widehat{z} \widehat{z}$ \\
\hline & & & 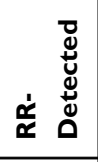 & z & 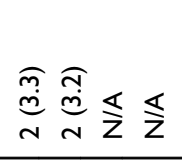 & 0000 & $\begin{array}{lllll}\stackrel{\infty}{\infty} & & & \widehat{\bar{N}} \\
N & 0 & 0 & N \\
\end{array}$ & 0000 \\
\hline & & & 离 & z & 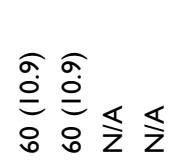 & 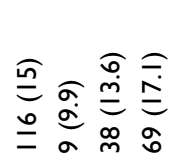 & 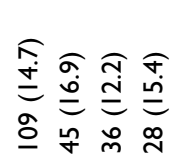 & 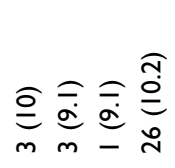 \\
\hline & & & 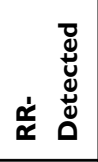 & z & 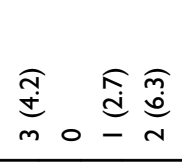 & 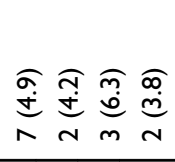 & 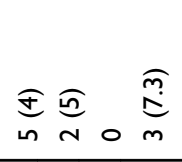 & 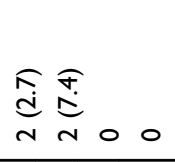 \\
\hline & & & 离 & z & 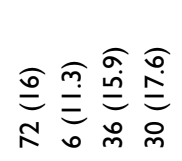 & 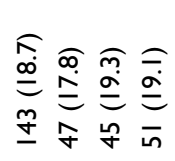 & 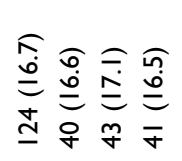 & 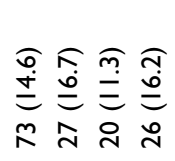 \\
\hline & & & 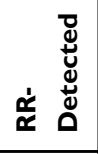 & $\frac{\subsetneq}{\mathbf{z}}$ & 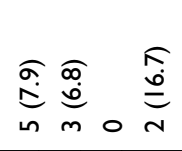 & 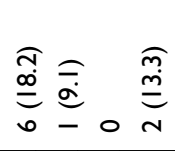 & 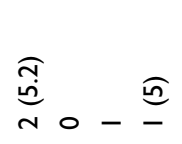 & 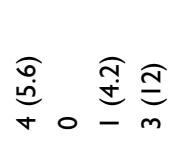 \\
\hline & & & 离 & z & 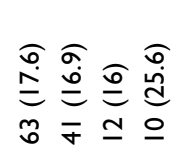 & 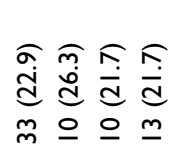 & 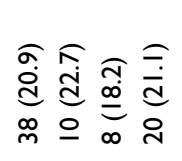 & 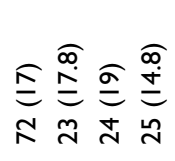 \\
\hline & & & 离 & z & 0 $0 \stackrel{\Sigma}{z}$ & 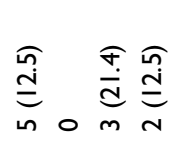 & 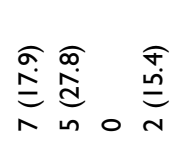 & 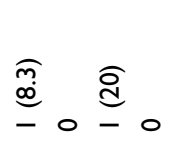 \\
\hline & & & 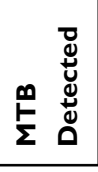 & z & 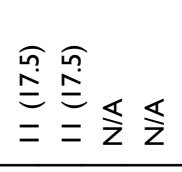 & 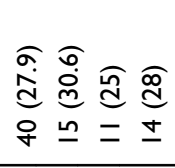 & 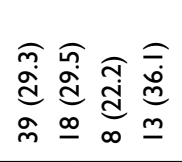 & 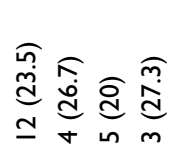 \\
\hline & & & & & 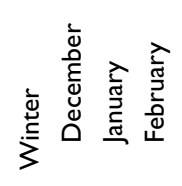 & 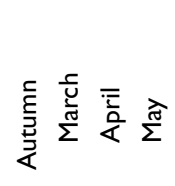 & 鹃导会总 & 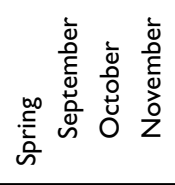 \\
\hline
\end{tabular}




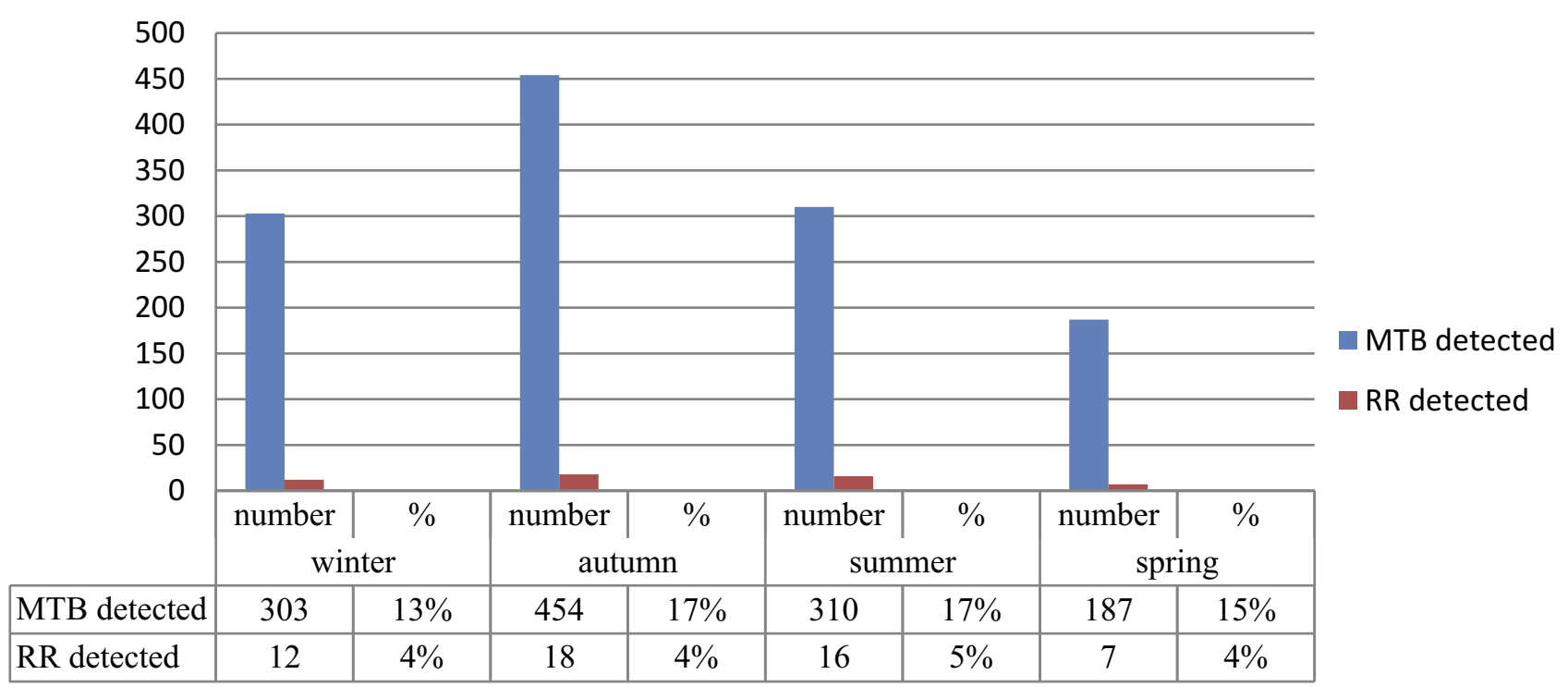

Figure 2 Graphical presentation of TB and rifampicin resistance at Hiwot Fana Specialized University Hospital, Eastern Ethiopia, January $2015-A p r i l ~ 2019$.

Ethiopia, ${ }^{16}$ Awi Zone, Northwest Ethiopia, ${ }^{17}$ and Addis and wollo, North-East Ethiopia. ${ }^{20}$ This difference Ababa, Ethiopia. ${ }^{18}$ However, this was higher than stu- might be due to the different methods of diagnosis, as dies from Addis Ababa, ${ }^{6}$ Agaro Southwest, Ethiopia, ${ }^{19}$ we used only GeneXpert assay while other studies

Table 4 Factor Associated With Tuberculosis By Sex, Age, Status Of HIV, History Of TB, And Residence Of Study Participants At Hiwot Fana Specialized University Hospital, Eastern Ethiopia, January 2015-April 2019

\begin{tabular}{|c|c|c|c|c|c|}
\hline \multirow[t]{2}{*}{ Variables } & \multicolumn{2}{|c|}{ MTB Detected } & \multirow[t]{2}{*}{ Crude OR $[95 \% \mathrm{CI}]$} & \multirow[t]{2}{*}{ Adjusted OR $[95 \% \mathrm{Cl}]$} & \multirow[t]{2}{*}{$P$-value } \\
\hline & Yes, $N(\%)$ & No, $\mathbf{N}(\%)$ & & & \\
\hline \multicolumn{6}{|l|}{ Sex } \\
\hline Male & $727(16.7)$ & 3,635 (83.3) & $0.847[0.75-0.96]$ & $0.84[0.75-0.96]$ & $0.006 *$ \\
\hline Female & $527(14.5)$ & $3,112(85.5)$ & 1 & 1 & \\
\hline \multicolumn{6}{|l|}{ Age } \\
\hline$\leq 14$ & $197(14.1)$ & $1,204(85.1)$ & $1.12[0.91-1.37]$ & $1.14[0.92-1.38]$ & 0.230 \\
\hline $15-29$ & $501(19.5)$ & $2,068(80.5)$ & $1.65[1.39-1.96]$ & $1.7[1.4 \mathrm{I}-1.98]$ & $0.001 *$ \\
\hline $30-44$ & $333(14.6)$ & $1,954(85.4)$ & $1.16[1.97-1.40]$ & $1.2[0.98-1.42]$ & 0.076 \\
\hline$\geq 45$ & $223(12.8)$ & $\mathrm{I}, 52 \mathrm{I}(87.2)$ & I & I & \\
\hline \multicolumn{6}{|l|}{ History of TB } \\
\hline Previous Rx & $29(27.6)$ & $76(72.4)$ & $0.48[0.31-0.74]$ & $0.5 \mathrm{I}[0.33-0.78]$ & $0.002^{*}$ \\
\hline New & I,225 (I5.5) & $6,67 \mid(84.5)$ & I & 1 & \\
\hline \multicolumn{6}{|l|}{ HIV status } \\
\hline Reactive & $19(26.0)$ & $54(74.0)$ & $0.52[0.31-0.87]$ & $0.51[0.30-0.86]$ & $0.013^{*}$ \\
\hline Unknown & $\mathrm{I}, \mathrm{I} 72(\mathrm{I} 5.4)$ & $6,452(84.6)$ & $0.76[0.42-1.36]$ & $0.51[0.40-1.32]$ & 0.298 \\
\hline Non-reactive & $63(20.7)$ & $24 \mid(79.3)$ & I & 1 & \\
\hline \multicolumn{6}{|l|}{ Resident } \\
\hline Rural & $1,015(16)$ & $5,323(84)$ & $0.87 \mid[0.75-1.02]$ & $0.86[0.74-1.0]$ & 0.052 \\
\hline Urban & $239(14.4)$ & $\mathrm{I}, 424(85.6)$ & I & I & \\
\hline
\end{tabular}

Note: *Statistically significant at $P$-value $<0.05$.

Abbreviations: $\mathrm{Cl}$, confidence interval; OR, odds ratio; Rx, retreatment; TB, tuberculosis; $\mathrm{N}$, number of mycobacterial tuberculosis cases detected. 
used culture, microscopy, and other molecular techniques for bacterial identification.

The trend of TB positivity rate in this study gradually decreased consecutively throughout the study period, at $19.3 \%$ in $2015,18.6 \%$ in $2016,18.4 \%$ in $2017,13.5 \%$ in 2018 , and $13 \%$ in 2019 . This finding is consistent with a report from Agaro and Nekemte in Ethiopia, ${ }^{7,19}$ and in China $^{21}$ in which the trend of TB steeply declined. But it was contradicted with a study from Gambella, West Ethiopia $^{22}$ and in Nigeria, ${ }^{23}$ in which the trend of TB fluctuated year to year. The occurrence of this difference in different years and countries can be affected by a higher tendency for clinicians to consider presumptive $\mathrm{TB}$, change in storage conditions of samples, change in lab SOPs or staff conducting the test; and maybe a different level of awareness of people about early treatment and diagnosis might also have great contribution for it. Moreover, in some parts of Ethiopia, the gradual decreasing of TB proportion could be influenced by the health extension program that planned to achieve important basic healthcare to prevent the spread of $\mathrm{TB}$ by increasing community awareness.

In this study, sex, age, previous history of TB, and HIV status of patients were found to be significantly associated with the cause of Mycobacterium tuberculosis. Male participants had a significantly higher proportion of TB cases than females. This agrees with a study reported from Jimma, Southwest, Ethiopia, ${ }^{24}$ Gondar, Northwest Ethiopia, ${ }^{25}$ Zambia, ${ }^{26}$ and Japan. ${ }^{27}$ However, it is not consistent with the finding from Northwest Ethiopia. ${ }^{17}$ This might be because males usually have more social contact in the community than females which helps them to contract a disease. A similar idea was reported from a study conducted in Arba Minch, Ethiopia that the greater mobility of males than females to visit and to come into contact with TB patients could contribute to catching higher infection among the males than females. ${ }^{28}$

The age group of 15-29 years was the most infected by TB, which was similar to studies reported from Ethiopia, ${ }^{13}$ Agaro, southwest Ethiopia, ${ }^{19}$ Gondar, Northwest Ethiopia, ${ }^{26}$ Central Ethiopia, ${ }^{29}$ Pakistan, ${ }^{30}$ and Singapore. ${ }^{31}$ This might be due to this age group being more sexually active and, hence, infected with HIV, which predisposes to TB. Disproportionately, a large burden of TB cases in this age group share a high number of total workforces, which could contribute to the poverty of one's country.

History of previous treatment is the other factor associated with TB in the present study. This is similar to reports from Ethiopia ${ }^{3}$ and Dessie, Northeast Ethiopia. ${ }^{20}$ But it contradicts the study reported from Matahara, Eastern Ethiopia. ${ }^{32}$ This difference might be due to different implementation of DOTs (direct observed treatments) strategy and different awareness of the society.

People living with HIV are more likely to have TB compared to people without HIV in the present study. This is comparable to a study from another part of Ethiopia. ${ }^{33}$ But it is not in line with a study from Sub-Saharan Africa. ${ }^{34}$ The difference might be due to different levels of CD4 count and advanced WHO clinical stage that may determine the immunity of individuals living with HIV. ${ }^{33}$

Furthermore, living in a rural area was not a frequently identified factor associated with TB in this study, which is similar to studies from Pakistan ${ }^{30}$ and North Ethiopia. ${ }^{20}$

On the other side, the seasonality of TB was higher in the summer followed by the autumn compared to another seasonal year in this study. Similar ideas were reported from Addis Ababa, Ethiopia, ${ }^{6}$ Pakistan, ${ }^{30}$ and China, ${ }^{9}$ with a peak in summer. Looking at TB cases by month, June and May show a high proportion, while the lowest proportion was documented in January in this study. In Uganda, a low proportion of TB was reported in December and a high one in July and October, ${ }^{12}$ and March was a Peak and October the lowest in Chile. ${ }^{35}$ The difference that TB proportion in different seasonal patterns is due to healthcare-seeking behavior may vary from season to season, with domestic work such as the harvest or going to market, and may extend to the number of people tested for TB. ${ }^{13}$ During autumn and at the beginning of the summer, when most of the infected people were recorded, rural residents have the resources and time to seek medical care, thus increasing the TB cases in Ethiopia. ${ }^{13}$

\section{Limitations Of The Study}

This research has some limitations. Since it was a hospitalbased study, it would not have been representative of the general population. The right residence of study participants in Hiwot Fana Specialized University Hospital after diagnosis as well as information on rainfall and humidity to describe the seasonality of TB was not well-known.

\section{Conclusion}

The trend of TB proportion decreased over the study period. The age category of 15-29 years was the most affected and a high proportion of TB was observed in previously treated patients. Male gender and being HIV positive are also factors significantly associated with TB. 
A high proportion of TB was detected in the summer and autumn. Moreover, TB was not significantly associated with the patient's living area.

Based on this study, attention should be given during the summer and autumn as high cases of TB were recorded. Healthcare facilities should be improved for timely diagnosis and treatment. All HIV positive patients should be screened by Gene Xpert, which gives quick results (within 2 hours) to identify new TB patients to reduce infection.

\section{List Of Abbreviations}

HRERC, Institutional Health Research Ethics and Review Committee, HFSUH, Hiwot Fana Specialized University Hospital; HIV, Human Immuno Virus, RR, Rifampicin resistant; MTB, Mycobacteria Tuberculosis; TB, Tuberculosis; WHO, World Health Organization.

\section{Availability Of Data And Materials}

The raw data set used/analyzed during the current study is available from the author on reasonable request.

\section{Acknowledgements}

The authors would express great gratitude to Hiwot Fana Specialized University Hospital for providing recorded data of study participants. DB conceived and designed the study. All authors contributed to data analysis, drafting or revising the article, gave final approval of the version to be published and agree to be accountable for all aspects of the work.

\section{Funding}

No funding was received to conduct this study.

\section{Disclosure}

The authors declare that they have no competing interests in this work.

\section{References}

1. Berju A, Belete H, Seleshe N, Araya M, Girm B. S+ Tb prevalence and associated factors among pregnant women ANC in North Gondar Zone Hospitals, Ethiopia. Inter J of Micro. 2019;1-6. doi:10.1155/ 2019/9432469.

2. Holmes KK, Bertozzi S, Bloom BR, et al. Major Infectious Diseases: Key Messages from Disease Control Priorities. 3rd ed. Washington, DC: World Bank; 2017.

3. Biadglegne F, Ulrich S, Arne CR. Multidrug-resistant tuberculosis in Ethiopia: efforts to expand diagnostic services, treatment and care. Antimicrob Resist Infect Control. 2014;3(31):1-10. doi:10.1186/20472994-3-31.
4. Global tuberculosis report 2018. World Health Organization.

5. Ethiopia Public Health Institute. Implementation Guideline for GeneXpert MTB/RIF Assay in Ethiopia Addis Ababa Ethiopia. Public Health Institute; 2014.

6. Bikila D, Yohannes W, Abdeta A, et al. Seasonality and trend analysis of PTB at SPHMMC, Addis Ababa, Ethio. Med J Aust. 2017;4 (2): 1054 .

7. Ejeta E, Beyene G, Balay G, Bonsa Z, Abebe G. Factors associated with unsuccessful treatment outcome in tuberculosis patients among refugees and their surrounding communities in Gambella Regional State, Ethiopia. PLoS One. 2018;13(10):1-15. doi:10.1371/journal. pone.0205468.

8. Yang X, Duan Q, Wang J, Zhang Z, Jiang G. Seasonal variation of newly notified pulmonary tuberculosis cases from 2004 to 2013 in Wuhan, China. PLoS One. 2014;9(10):1-10: e108369.

9. Balcells AE, Patricia G, Camila T, et al. Association of vitamin $D$ deficiency, season of the year, and LTBs infection among household contacts. PLoS One. 2017;4(12):1-15:e0175400.

10. Kumar V, Abhay S, Mrinmoy A, Shailaja D, Anita K, Saudan S. Seasonality of tuberculosis in Delhi, India: a time series analysis. Tuberculosis Res Treat. 2014;2014:1-5. doi:10.1155/2014/514093.

11. Wubuli A, Li Y, Xue F, Yao X, Upur H, Wushouer Q. Seasonality of active tuberculosis notification from 2005 to 2014 in Xinjiang, China. PLoS One. 2017;12(7):12:e0180226. doi:10.1371/journal.pone.0180226.

12. Jaganath D, Wobudeya E, Sekadde MP, Nsangi B, Haq H, Cattamanchi A. Seasonality of childhood tuberculosis cases in Kampala, Uganda, 2010-2015. PLoS One. 2019;14(4):e0214555. doi:10.1371/journal.pone.0214555.

13. Gashu Z, Jerene D, Datiko DG, et al. Seasonal patterns of tuberculosis case notification in the tropics of Africa: a six-year trend analysis in Ethiopia. PLoS ONE. 2018;13(11):e0207552. doi:10.1371/journal. pone. 0207552 .

14. Mohammed SH, Ahmed MM, Al-Mousawi AM, Azeez A. Seasonal behavior and forecasting trends of tuberculosis incidence in Holy Kerbala, Iraq. Int J Myco. 2018;7:361-367.

15. Abate D, Bineyam T, Mohammed A, Sibhatu B. Epidemiology of anti-tuberculosis drug resistance patterns and trends in tuberculosis referral hospital in Addis Ababa, Ethiopia. BMC Infect Dis. 2012;5 (462):1-6.

16. Derbie A, Seble W, Daniel M, et al. Xpert MTB/RIF assay for the diagnosis of Mycobacterium tuberculosis and its Rifampicin resistance at Felege Hiwot and Debre Tabor Hospitals, Northwest Ethiopia: a preliminary implementation research. Ethiop. J. Health Dev. 2016;30(2):61-63.

17. Alemu T, Hordofa G. Trend in magnitude of tuberculosis in Awi Zone, Northwest Ethiopia: a five year tuberculosis surveillance data analysis. BMC Res. 2019;12(209):1-5.

18. Arega B, Fiqrte M, Yitagesu G. Prevalence of rifampicin resistant Mycobacterium tuberculosis among presumptive tuberculosis patients in selected governmental hospitals in Addis Ababa, Ethiopia. BMC Infect Dis. 2019;19(307):1-5. doi:10.1186/s12879019-3943-1.

19. Ali H, Zeynudin A, Mekonnen A, Abera S, Ali S. Smear positive pulmonary tuberculosis prevalence amongst patients at agaro teaching health center, south west Ethiopia. Ethiop J Health Sci. 2012;22:1.

20. Yeshi M, Abdurahaman S, Genet M, Fenta DG. Assessment of extra pulmonary tuberculosis using gene xpert MTB/RIF assay and fluorescent microscopy and its risk factors at Dessie Referral Hospital, Northeast Ethiopia. Biomed Res Int. 2018;1-10.

21. Ukwaja KN, Isaac A, Ngozi AI, Chijioke O, Chika I. Trend in case detection rate for all tuberculosis cases notified in Ebonyi, Southeastern Nigeria during 1999 - 2009. Pan Afr Med J. 2013;16.

22. Demeke D, Mengistu L, Jango B. Trend of tuberculosis and treatment outcomes in gambella region with special emphasize on Gambella Regional Hospital, Western Ethiopia. Mycobacterial Dis. 2013;3 (2):1-8. 
23. Asebe G, Gobena A, Ketema T. Ten year's tuberculosis trend in Gambella Regional Hospital, South Western Ethiopia. Malaysian J Med Biol Res. 2014;1(1):18-25. doi:10.15590/mjmbr/2014/v1i1/ 53716.

24. Tibebu H, Habtemu JH. The proportion of student tuberculosis cases and treatment outcome at Jimma University Medical Center: 5-Year Retrospective Study. Tuberculosis Res Treat. 2019;2019:1-7.

25. Muluye D, Belete B, Eden W, Andebet A. Prevalence of tuberculous lymphadenitis in Gondar University Hospital, Northwest Ethiopia. BMC Public Health. 2013;13(435):1-5. doi:10.1186/1471-2458-13-435.

26. Kapata N, Pascalina C-K, Justin OG, et al. Trends of Zambia's tuberculosis burden over the past two decades. Trop Med Int Health. 2011;16 (2):1404-1409. doi:10.1111/j.1365-3156.2011.02849.x.

27. Manabe T, Jin T, Koichiro K. Seasonality of newly notified pulmonary tuberculosis in Japan, 2007-2015. BMC Infect Dis. 2019;19 (497):1-8. doi:10.1186/s12879-019-3957-8.

28. Khan AQ, Wako A, Ayalew B, Tefera M, Tadessa y. prevalence of Tuberculosis in Males and Females in Arba Minch Town of South Ethiopia. J. Med. Sci. 2013;13(5):396-400.

29. Hamusse SD, Meaza D, Bernt L. Trends in TB case notification over fifteen years: the case notification of 25 districts of Arsi zone of Oromiya Regional State, Central Ethiopia. BMC Public Health. 2014;14:304. doi:10.1186/1471-2458-14-304.
30. Khaliq A, Syeda AB, Chaudhry MN. Seasonality and trend analysis of tuberculosis in Lahore, Pakistan from 2006 to 2013. J Epidemiol Glob Health. 2015;(5):397-403.

31. Wah W, Das S, Earnest A, et al. Time series analysis of demographic and temporal trends of tuberculosis in Singapore. BMC Public Health. 2014;14(1121):1-10. doi:10.1186/14712458-14-1121.

32. Yohanes A, Solomon A, Solomon A. Smear positive pulmonary tuberculosis among suspected patients attending metehara sugar factory hospital; eastern Ethiopia. Afr Health Sci. 2012;12(3):325-330.

33. Tesfaye B, Animut A, Alemu G, Abriham Z, Cheru T, Bekalu K. The twin epidemics: prevalence of TB/HIV coinfection and its associated factors in Ethiopia: a systematic review and meta-analysis. PLoS One. 2018;10(13):1-18

34. Nagua TJ, Aboud S, Mwiru R, et al. Tuberculosis associated mortality in a prospective cohort in Sub Saharan Africa: association with HIV and antiretroviral therapy. Int J Infect Dis. 2017;2017(56):39-44. doi:10.1016/j.ijid.2017.01.023.

35. Balcells ME, GarcõÂa P, Tiznado C, et al. Association of vit D deficiency, season of the year, and LTB infection among household contacts. PLoS One. 2017;12(4):e0175400. doi:10.1371/journal.pone.0175400.
Risk Management and Healthcare Policy

\section{Publish your work in this journal}

Risk Management and Healthcare Policy is an international, peerreviewed, open access journal focusing on all aspects of public health, policy, and preventative measures to promote good health and improve morbidity and mortality in the population. The journa welcomes submitted papers covering original research, basic science, clinical \& epidemiological studies, reviews and evaluations,

\section{Dovepress}

guidelines, expert opinion and commentary, case reports and extended reports. The manuscript management system is completely online and includes a very quick and fair peer-review system, which is all easy to use. Visit http://www.dovepress.com/testimonials.php to read real quotes from published authors. 